\title{
Depuración aerobia de las aguas de condensación del proceso de concentración térmica del alpechín.
}

\author{
Por R. Borja Padilla, J. A. Fiestas Ros de Ursinos, M. M. Durán Barrantes y M. Luque González. \\ Instituto de la Grasa y sus Derivados (C.S.I.C.) Avda. Padre García Tejero n. 4 - 41012 - SEVILLA.
}

\section{RESUMEN}

Depuración aerobia de las aguas de condensación del proceso de concentración térmica del alpechin.

Se ha efectuado un estudio del proceso de depuración aerobia, en régimen discontinuo, de los condensados resultantes del proceso de concentración térmica del alpechín.

Se comprueba que el $80 \%$ de la materia orgánica presente en este agua se elimina a partir del tercer día de fermentación.

La velocidad de eliminación de sustrato sigue una cinética de orden cero para altas concentraciones del mismo y una cinética de primer orden para bajas concentraciones de materia orgánica, es decir, durante los últimos dias de fermentación.

Se aplica el modelo de Michaelis-Menten de eliminación de sustrato para la obtención de los parámetros cinéticos. $q_{\max }$ y $\mathrm{K}_{\mathrm{s}}$ que rigen este proceso.

PALABRAS-CLAVE: Agua de condensación - Alpechín Cinética - Depuración aerobia.

\section{SUMMARY}

Aerobic purification of condensed water from thermal concentration process of olive mill wastewater.

A study of aerobic treatment in batch regime of condensed water from thermal concentration process of olive mill wastewater was carried out

An $80 \%$ of wastewater organic substances was removal after the third day of fermentation.

The substrate removal rate follows a zero-order kinetic for high concentrations, and a first-order kinetic for low organic matter concentration, during the last days of fermentation.

The kinetic parameters $\left(q_{\max }\right.$ and $\left.K_{s}\right)$ were obtain by Michaelis-Menten model.

KEY-WORDS: Aerobic depuration - Condensation water Kinetics - Olive mill wastewater.

\section{INTRODUCCIÓN}

Uno de los sistemas físicos utilizados para la depuración del alpechín es el de concentración térmica, consistente en la eliminación de parte del agua, utilizando evaporadores o concentradores de múltiple efecto, para evitar elevados consumos energéticos (1).
La aplicación de este proceso disminuye en un $70-75 \%$ el volumen de este agua residual y permite la obtención de concentrados de alpechín que pueden tener aplicación para su adición a los piensos por su valor alimenticio, o bien como fertilizantes en agricultura 0 , incluso, previa investigación correspondiente, como medio de cultivo para el desarrollo de microorganismos de posible interés químico-farmaceútico (2) (3) (4) (5).

No obstante el agua procedente de la condensación de los vapores contiene la mayor parte de los componentes volátiles del alpechín, así como pequeñas cantidades de este por arrastre o proyecciones. Esto hace que dicha agua requiera un proceso posterior de depuración para su vertido o posible utilización en la propia almazara.

El objetivo de este trabajo es el estudio del proceso de depuración aerobia en régimen discontinuo de los condensados procedentes de la concentración térmica del alpechín, con obtención de las constantes cinéticas que rigen este proceso.

\section{PARTE EXPERIMENTAL.}

\subsection{Equipo experimental.}

Para llevar a cabo el proceso de depuración se utiliza un reactor de 2 litros de capacidad, que contiene un volumen total de líquido de 1,5 litros. El grado de mezcla adecuado se consigue con una pequeña turbina que gira a $360 \mathrm{rpm}$. Se utiliza un flujo de aire de $750 \mathrm{ml} /$ minuto suministrado a través de un difusor cerámico.

\subsection{Características del agua condensada.}

Las características del agua condensada del proceso de concentración térmica del alpechín se muestran en la tabla . 
Tabla I

Características de los condensados de alpechín utilizados.

\begin{tabular}{|ll} 
Color & Amarillento \\
$\mathrm{pH}$ & 3,50 \\
Acidez Total & $2,10 \mathrm{~g} / \mathrm{l}$ (ácido acético) \\
$\begin{array}{l}\text { Acidez volátil } \\
\text { Demanda química }\end{array}$ & $2,05 \mathrm{~g} / \mathrm{l}$ (ácido acético) \\
$\begin{array}{l}\text { de oxígeno } \\
\text { deno }\end{array}$ & $5,00 \mathrm{~g} / \mathrm{l}$
\end{tabular}

Su composición en ácidos volátiles, obtenida por cromatografía gaseosa, se recoge en la tabla II.

Tabla II

Composición en ácidos volátiles del condensado de alpechín. Análisis cromatográfico.

$\begin{array}{ll}\text { Acido Acético } & 35,5 \% \\ \text { Acido Propiónico } & 18,7 \% \\ \text { Acido Butírico } & 43,1 \% \\ \text { Acido Valeriánico } & 0,4 \% \\ \text { Acido Isovaleriánico } & 0,3 \%\end{array}$

\subsection{Acondicionamiento del condensado de} alpechín.

Previamente a la realización del proceso de depuración aerobia, este agua residual se neutraliza con $\mathrm{CO}_{3} \mathrm{Na}_{2}$ con objeto de conseguir la necesaria capacidad buffer carbonato-bicarbonato imprescindible para el buen funcionamiento del proceso aerobio. Dado el pequeñísimo contenido de nitrógeno y fósforo de este agua, se adicionan estos nutrientes para mantener la relación DQO:N:P en 100:5:1 valores recomendables para el óptimo desarrollo de los sistemas aerobios (6).

\subsection{Aclimatación de la biomasa aerobia.}

Previamente a la realización de los experimentos y con vistas a la aclimatación de la biomasa aerobia del proceso se llevan a cabo unos experimentos iniciales de adaptación consistentes en la siembra inicial con $50 \mathrm{ml}$ de lodos procedentes de una depuradora aerobia (Empresa Municipal de Aguas de Sevilla S.A., EMASESA) en el reactor que contiene 1,5 litros de condensados del alpechín; el reactor se mantiene en agitación y aireación durante un período de 7 días. Al cabo de este tiempo y tras una breve decantación se separa el líquido sobrenadante de los lodos bacterianos que permanecen en el fondo del reactor, añadiéndose nuevamente el mismo volumen de agua residual. Se repite esta operación durante 6 semanas consecutivas, de tal manera que tras este periodo de tiempo los niveles de eliminación de DQO del agua se mantienen constantes. Conseguido este objetivo se separan la biomasa desarrollada $y$ adaptada por decantación y se inician los experimentos.

\subsection{Procedimiento experimental}

Para la realización de los experimentos se toman $100 \mathrm{ml}$ de esta biomasa adaptada (cuyo contenido en sólidos en suspensión volátiles es de $4,0 \mathrm{~g} /$ ) y se completa hasta los 1,5 litros de volumen con condensados procedentes de la concentración térmica del alpechín. Se mantienen en agitación homogénea y aireación durante un periodo de 7 días, en régimen discontinuo.

Diariamente se toma una pequeña muestra $(20$ $\mathrm{ml}$ ) del interior del reactor para determinar el contenido en sólidos en suspensión volátiles (SSV) y el valor de la DQO del agua con el transcurso del tiempo.

\subsection{Técnicas analíticas.}

Los análisis se realizan de acuerdo con el "Standard Methods for the Examination of Water and Wastewater" (7).

\section{RESULTADOS EXPERIMENTALES}

En la figura 1 se recoge la variación de la concentración de sustrato de los condensados de alpechín, medida como DQO $(\mathrm{g} / \mathrm{l})$ en función del tiempo de fermentación (días).

En la tabla III se exponen los valores de concentración de sólidos en suspensión volátiles (g/l) para los distintos tiempos a lo largo de este proceso de digestión aerobia.

\section{DISCUSIÓN DE LOS RESULTADOS}

Como se observa en la figura 1 , el $80 \%$ de la materia orgánica inicial (DQO) se elimina después del 3. día de aireación, existiendo una disminución muy acusada de este parámetro, hasta alcan- 


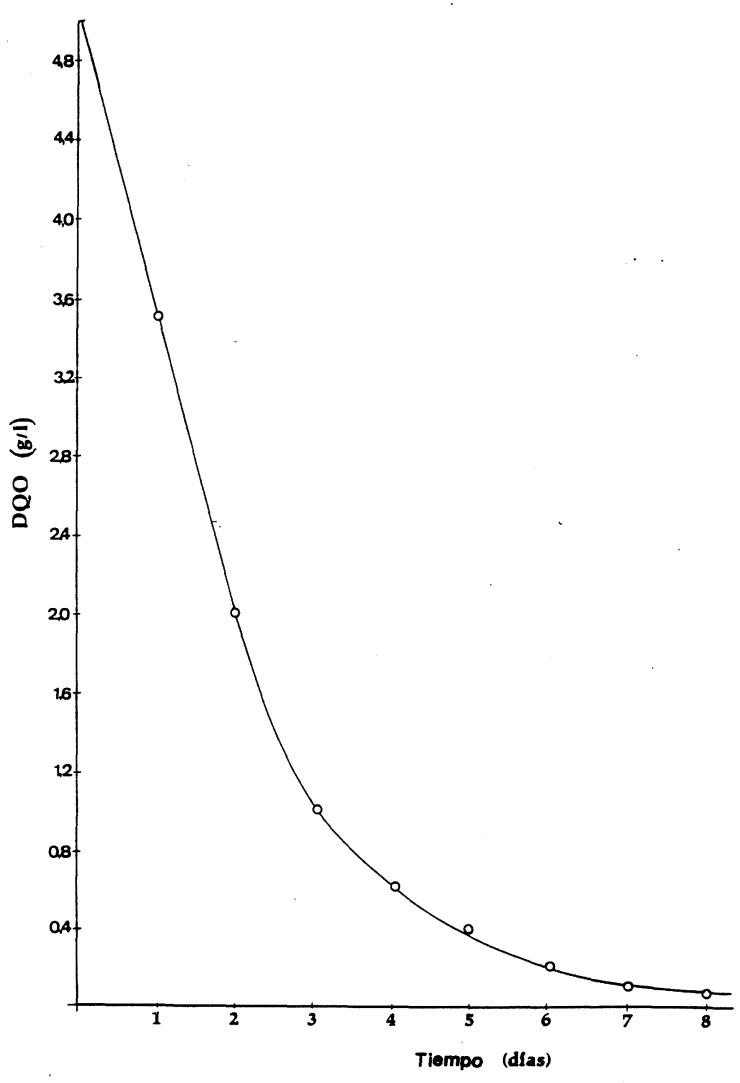

Figura 1

Variación de la concentración de sustrato, medida como DQO, en función del tiempo de fermentación.

zar un valor mínimo de $0,1 \mathrm{~g} / \mathrm{l}$, cantidad correspondiente a la fracción no biodegradable. Este valor se mantiene constante a partir del 7.9 día de aireación.

Durante los cinco primeros días de fermentación existe un aumento gradual del contenido de biomasa bacteriana (SSV), período correspondiente a la fase de sintesis celular, al existir en el medio cantidad de sustrato suficiente para el crecimiento y desarrollo de nuevos microorganismos. A partir del $5 .^{\circ}$ día de fermentación existe un paulatino descenso en el contenido de lodos bacterianos, debido a que la velocidad de destrucción celular supera a la de síntesis; este tramo corresponde a la fase de metabolismo endógeno del sistema (tabla III).
Existen dos diferencias fundamentales entre el modo de operar de un reactor continuo y de uno discontinuo. En primer lugar, a diferencia de lo que ocurre en un reactor discontinuo, la DQO del agua residual en el reactor continuo permanece constante cuando opera en condiciones de estado estacionario, valor que corresponde generalmente a la zona de bajas concentraciones de sustrato en el reactor discontinuo. En segundo lugar, la concentración de lodos bacterianos en el reactor continuo se mantiene aproximadamente constante en un valor determinado, en condiciones estacionarias, a diferencia de lo que ocurre en el reactor discontinuo, como el que nos ocupa (8).

Se pueden distinguir dos valores puntuales de tiempo de digestión, equiparables a otros tantos tiempos de residencia típicos en el reactor que opera en régimen continuo. En primer término, como se observa en la figura 1, durante el tercer día de fermentación el valor de la DQO se encuentra en $1,0 \mathrm{~g} / \mathrm{l}$, correspondiente a una eliminación del $80 \%$ respecto del valor inicial $(5,0 \mathrm{~g} / \mathrm{l})$ mientras que el contenido en lodos bacterianos está en 1,85 g/l de SSV (tabla III). Estos valores se encuentran dentro del intervalo habitual correspondiente al proceso de "lodos activos" convencional del reactor continuo (75-95\% de reducción de DQO y 1,5-3,0 g/l de SSV) (8).

En segundo lugar, durante el 5. día de digestión se alcanza el máximo valor en la concentración de SSV $(3,4 \mathrm{~g} / \mathrm{l}$, según tabla III), lográndose una eliminación del $92 \%$ de la DQO de este residuo. Estos valores se encuentran dentro del margen correspondiente a procesos de "aireación extensiva" para el reactor en régimen continuo (90-100\% de eliminación de DQO y de 3,0 a $5,0 \mathrm{~g} / \mathrm{l}$ de SSV) (8).

A partir de la representación correspondiente a la variación de concentración de sustrato con el tiempo (figura 1), se obtienen los valores puntuales de la velocidad de eliminación de sustrato, por medio de la pendiente de la tangente a la curva, para los distintos tiempos de digestión. En la tabla IV se exponen los valores de este parámetro para cada concentración de sustrato y tiempo de fermentación. Del estudio detallado de esta tabla se observan dos hechos destacables:

Tabla III

Valores de la concentración de sólidos en suspensión volátiles ( $g / l)$ en función del tiempo de digestión (dias).

$\begin{array}{lcccccrrr}\text { Tiempo (días) } & 0 & 1 & 2 & 3 & 4 & 5 & 6 & 7 \\ \operatorname{SSV}(g / 1) & 0,25 & 0,55 & 1,20 & 1,85 & 2,60 & 3,40 & 3,00 & 2,70\end{array}$


Tabla IV

Valores de la velocidad de eliminación de sustrato, $\mathrm{dS} / \mathrm{dt}$, para los distintos tiempos y concentraciones de sustrato, $S_{e}$ del proceso de digestión.

$\begin{array}{lccccccc}\text { Tiempo (días) } & 1 & 2 & 3 & 4 & 5 & 6 & 7 \\ S_{m}(g / 1) & 3,5 & 2,0 & 1,0 & 0,6 & 0,4 & 0,2 & 0,1 \\ \mathrm{dS}_{-1} / \mathrm{dt} \text { (g/1/día) } & 1,51 & 1,51 & 0,51 & 0,34 & 0,21 & 0,11 & 0,03\end{array}$

a) Para altas concentraciones de sustrato $\left(\mathrm{S}_{\theta}\right.$ $\geq 2,0 \mathrm{~g} / \mathrm{l}$ de $\mathrm{DQO}$ ), es decir, durante los dos primeros días de digestión, la velocidad de eliminación de sustrato se mantine constante $\left(d S_{e} / d t=1,51\right)$ e independiente de la concentración del mismo; por tanto para este intervalo de concentraciones el proceso de eliminación de sustrato sigue una cinética de orden cero.

b) Para bajas concentraciones de sustrato ( $\mathrm{S}_{\mathrm{e}}$ $\leq 1,0 \mathrm{~g} / \mathrm{l}$ de $\mathrm{DQO}$ ), correspondientes a tiempos de digestión entre 3 y 7 días, la velocidad de eliminación de sustrato es directamente proporcional a la concentración del mismo. Esto nos indica que para este rango de concentraciones, la velocidad de eliminación presenta una cinética de primer orden. De esta forma, utilizando el método de mínimos cuadrados, los valores de velocidad de eliminación se linealizan frente a los valores de concentración de sustrato, $\mathrm{S}_{\theta}$, para los días 3,4 , 5,6 y 7, obteniéndose los siguientes parámetros:

Coeficiente de regresión lineal $=0,995$

Ordenada en el origen $=0,001$

Pendiente $=0,521$

Se observa que, siendo la ordenada en el origen de esta correlación prácticamente nula, existe un buen ajuste lineal entre estos parámetros para este rango de bajas concentraciones de sustrato, lo que demuestra que la cinética de eliminación de materia orgánica, es de primer orden en este intervalo de concentraciones de sustrato.

Para obtener los datos cinéticos que rigen este proceso de depuración aerobia se aplica la ecuación de Michaelis-Menten de eliminación de sustrato $(8)$ :

donde:

$$
q=q_{\max } \frac{s_{\theta}}{K_{s}+S_{\theta}}
$$

$q$ = velocidad especifica de eliminación de sustrato, definida como la variación de la concentración de sustrato por unidad de tiempo y de biomasa (g/l DQO/ (dia g/l SSV)).

$q_{\max }=$ velocidad máxima específica de eliminación de sustrato.
$S_{e}=$ concentración de sustrato en el reactor.

$\mathrm{K}_{\mathrm{s}}=$ constante de Michaelis-Menten.

Previamente a la aplicación de este modelo cinético se debe comprobar que los datos experimentales se adaptan a las características de la ecuación propuesta.

Así pues, para altas concentraciones de sustrato, se cumple:

$$
\mathrm{S}_{\mathrm{e}} \gg \mathrm{K}_{\mathrm{s}}
$$

con lo que $\mathrm{K}_{\mathrm{s}}$ puede despreciarse del denominador de la ecuación (1), quedando:

$$
q=q_{\max }
$$

ecuación que nos indica que para este intervalo de concentraciones la velocidad de eliminación de sustrato es constante e independiente de la concentración de éste (cinética de orden cero).

En cambio, para bajas concentraciones de materia orgánica.

$$
\mathrm{S}_{\mathrm{e}} \ll \mathrm{K}_{\mathrm{s}}
$$

con lo que $S_{\theta}$ puede eliminarse del denominador de la ecuación (1), quedando:

$$
q=\frac{q_{m a x}}{K_{s}} \cdot S_{\theta}
$$

al ser $q_{\max }$ y $K_{s}$ constantes, $q_{\text {max }} / K_{s}=K=$ constante

$$
\mathrm{q}=\mathrm{K} \cdot \mathrm{S}_{\boldsymbol{\theta}}
$$

ecuación que nos indica que para bajas concentraciones de sustrato, la velocidad de eliminación del mismo presenta una cinética de primer orden, tal y como se comprueba con los datos experimentales (tabla IV).

Una vez comprobado el ajuste de los datos experiementales a las características de la ecuación cinética propuesta, se determinan los parámetros cinéticos $\mu_{\max }$ y $\mathrm{K}_{\mathrm{s}}$. Para ello, tomando el recíproco de la ecuación (1) se obtiene:

$$
\frac{1}{q}=\frac{1}{q_{\operatorname{máx}}}+\frac{K_{s}}{q_{\max }} \cdot \frac{1}{s_{\theta}}
$$


de forma que a partir de la representación de 1/ $q$ frente a $1 / S_{\theta}$ se debe obtener una línea recta, de ordenada en el origen $1 / q_{\max }$ y pendiente $K_{s} /$ $\mathrm{q}_{\max }$. Esta representación gráfica conocida con el nombre de representación de Lineweaver-Burk, permite la determinación de los parámetros cinéticos $\mathrm{q}_{\max }$ y $\mathrm{K}_{\mathrm{s}}(8)$.

Cuando se utiliza la DQO, como parámetro de medida de la concentración de la materia orgánica de un sistema y existe una fracción de la misma no biodegradable, como es nuestro caso, la ecuación de Michaelis se puede poner de la forma:

$$
q=q_{\max } \cdot \frac{\left(S_{e}-S_{n}\right)}{K_{s}+\left(S_{e}-S_{n}\right)}
$$

siendo $S_{n}$ la fracción de concentración de sustrato no biodegradable (en nuestro caso $S_{n}=0,1 \mathrm{~g} / \mathrm{l}$ ):

De esta forma, la ecuación correspondiente a la representación de Lineweaver-Burk queda:

$$
\frac{1}{q}=\frac{1}{q_{\text {max }}}+\frac{K_{s}}{q_{\text {max }}} \cdot \frac{1}{\left(S_{\theta}-S_{n}\right)}
$$

En la figura 2 se representan los valores de $1 / q$ frente al cociente $1 /\left(S_{e}-S_{n}\right)$.

Los valores de $1 / q$ se obtienen a partir de la expresión:

$$
\frac{1}{q}=\frac{X}{S_{0}-\left(S_{e}-S_{n}\right)}
$$

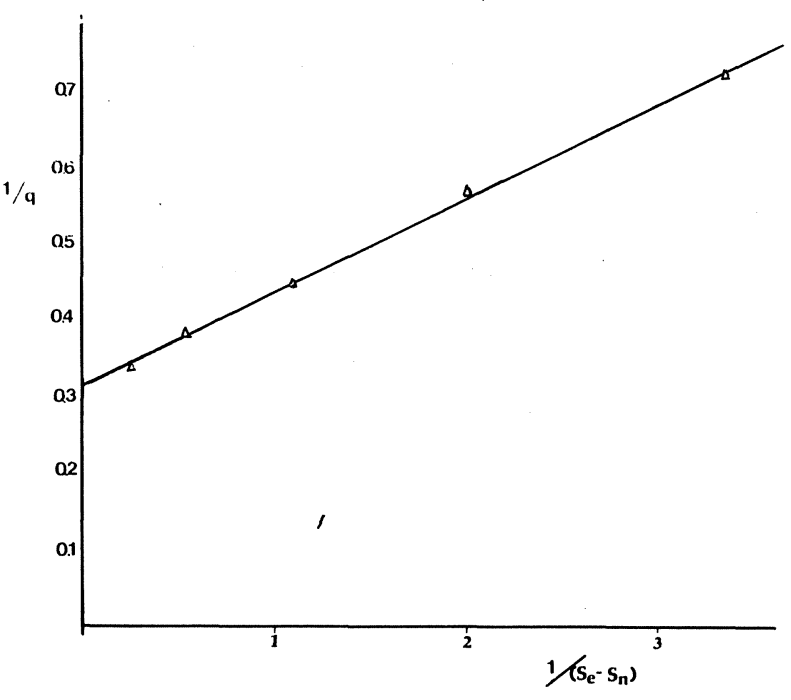

Figura 2

Representación de Lineweaver-Burk.
Siendo:

$X$, la concentración de biomasa bacteriana, medida como sólidas en suspensión volátiles (tabla III).

$S_{o}$, la concentración inicial de sustrato $(5,0 \mathrm{~g} /$ ( de DQO)

Las parejas de valores, $1 / q-1 /\left(S_{e}-S_{n}\right)$, se ajustan a una línea recta utilizando el método de mínimos cuadrados, obteniéndose los siguientes resultados:

Coeficiente de correlación $=0,998$

Ordenada en el origen $=0,317$

Pendiente $=0,124$

Teniendo en cuenta la ecuación (7), se obtienen los valores de los parámetros cinéticos $q_{\text {máx }} y$ $\mathrm{K}_{\mathrm{s}}$ :

$$
\begin{aligned}
& \mathrm{q}_{\text {máx }}=3,14 \frac{\mathrm{g} / \mathrm{l} \mathrm{DQO}}{\text { día } \cdot \mathrm{g} / \mathrm{SSV}} \\
& \mathrm{K}_{\mathrm{s}}=0,39 \mathrm{~g} / \mathrm{I} \mathrm{DQO}
\end{aligned}
$$

parámetros que representan la actividad cinética de los microorganismos responsables de este proceso aerobio.

\section{CONCLUSIONES}

1.- La depuración de los condensados procedentes de concentración térmica del alpechín se puede realizar via aerobia, eliminándose el $80 \%$ de la materia orgánica de los mismos con tres días de fermentación en régimen discontínuo.

2.- Para altas concentraciones de sustrato, intervalo correspondiente a los dos primeros días de aireación, la velocidad de eliminación de materia orgánica sigue una cinética de orden cero, presentando un valor constante e independiente de la concentración de aquel.

3.- Para bajas concentraciones de sustrato, zona comprendida entre el 3. y $7 .^{\circ}$ día de fermentación, la velocidad de eliminación de sustrato muestra una cinética de primer orden, al presentar valores directamente proporcionales a la concentración del sustrato.

4.- A través del modelo cinético de eliminación de sustrato de Michaelis-Menten se obtienen los parámetros cinéticos que caracterizan a este proceso aerobio. 


\section{AGRADECIMIENTOS}

Queremos hacer constar nuestro agradecimiento a D. ${ }^{\text {a }}$ Carmen Sánchez y a D. a Antonia Escobar por su eficaz ayuda y colaboración.

\section{BIBLIOGRAFIA}

1. Valenzuela Ruiz, G.- "Thermal concentration of vegetation water".- Symposium on Olive by products valorization. FAO (1986) 173-177.

2. Annesini, M. C.; Giona, A. R.; Gironi, F. and Pochetti, F. "Treatment of olive oil wastes by distillation".- Water Treatment Journal, 6 (1983) 245-248.

3. Vitagliano, M.- "Utilizzazione racionale delle acque di vegetazione delle oliven.- Oli Grassi Derivati. 11 (1975) 3840.

4. Arpino, A, and Cavola, C.- "Lo smaltimento delle acque di vegetazione provenienti dagli impianti di estrazione dell'olio d'oliva. L'Incineramento delle acque di vegetazione".- Riv. Ital. Sostanze Grasse LIV (1978) 24-28.

5. Amirante, P., and Mongelli, C.- "Prove sperimentali di trattamento delle acque reflue di un oleificio con impianto di incenerimento".- Riv. Ital. Sostanze Grasse LIX (1982) 295300.

6. Fiestas Ros de Ursinos, J. A.- "Directrices actuales en la depuración de aguas residuales de carácter orgánico". Química Industria, 30 (6) (1984) 431-435.

7. American Public Health Association (APHA). "Standar Methods for the Examination of Water and Wastewater".- 16 th edition, (1985) Washington.

8. Ramalho, R. S.- "Introduction to Wastewater Treatment Processes".- Second edition. Ed. Academic Press, 1983.

(Recibido: Febrero 1991) 